\title{
DESEMPENHO ECONÔMICO DAS EMPRESAS FAMILIARES E NÃO FAMILIARES NA CRISE DE 2012
}

\section{Economic performance of family and non-family enterprises in the 2012 Crisis}

\begin{abstract}
Micheli Aparecida Lunardi
E-mail: micheli.lunardi@yahoo.com.br

Mestra em Ciências Contábeis pela Universidade Regional de Blumenau; Doutoranda em Ciências

Contábeis e Administração pela Universidade Regional de Blumenau; Bolsista Capes no Programa de Pós-graduação em Ciências Contábeis do Departamento em Ciências Contábeis da Universidade

Regional de Blumenau.

Endereço profissional: Rua Antônio da Veiga, 140, Itoupava Seca, 89030-903, Blumenau, Santa

Catarina, Brasil.

https://orcid.org/0000-0003-0622-928X

Nelson Hein

E-mail: hein@furb.br

Pós-doutor pela Associação Instituto Nacional de Matemática Pura e Aplicada e pela Anderson

School of Management da Universidade do Novo México (EUA); Doutor em Engenharia de Produção pela Universidade Federal de Santa Catarina; Professor no Programa de Pós-graduação em Ciências Contábeis da Universidade Regional de Blumenau.

https://orcid.org/0000-0002-8350-9480
\end{abstract}

Adriana Kroenke E-mail: akroenke@furb.br

Doutora em Métodos Numéricos em Engenharia pela Universidade Federal do Paraná; Mestra em Ciências Contábeis pela Universidade Regional de Blumenau; Professora no Programa de Pósgraduação em Ciências Contábeis da Universidade Regional de Blumenau. https://orcid.org/0000-0001-6625-3017 


\section{Resumo}

Esta pesquisa consistiu em analisar o comportamento do desempenho econômico das empresas familiares e não familiares na Crise de 2012. Para tanto, analisaram-se as empresas brasileiras listadas na B3 (Brasil, Bolsa, Balcão) e desenvolveu-se um estudo descritivo, documental e quantitativo, com a utilização de ranking, distância $\mathrm{DP}_{2}$. O período de análise compreendeu os anos de 2008 a 2016. Os resultados revelaram que nos anos de 2011, 2012 e 2013 as empresas familiares apresentaram melhor colocação no ranking de desempenho econômico das empresas analisadas. Conclui-se que houve uma mudança no comportamento econômico das empresas familiares e não familiares principalmente nos anos próximos à Crise de 2012, sendo que as empresas familiares passaram a ocupar o primeiro lugar no ranking de desempenho econômico, quando anteriormente era mantido pelas empresas não familiares. Assim, em um cenário de crise o desempenho econômico das empresas familiares é superior ao das empresas não familiares. Como contribuição, o estudo apresenta o comportamento econômico das empresas familiares e não familiares, indicando como o desempenho econômico das empresas familiares e não familiares se comporta em um cenário de crise, demonstrando que as empresas familiares tendem a manter o desempenho econômico maior.

Palavras-chave: Desempenho econômico. Empresas familiares. Empresas não familiares. Crise 2012.

\section{Abstract}

This research consisted of analyzing the behavior of the economic performance of family and non-family businesses in the Crisis of 2012. To this end, we analyzed the Brazilian companies listed in B3 (Brazil, Bolsa, Balcão) and developed a descriptive, documentary and with the use of ranking, distance $D P_{2}$. The analysis period comprised the years from 2008 to 2016 . The results revealed that in the years 2011, 2012 and 2013 the family companies presented better ranking in the economic performance ranking of the analyzed companies. It was concluded that there was a change in the economic behavior of family and non-family businesses, especially in the years near the 2012 Crisis, and family companies started to occupy the first place in the economic performance ranking, when previously it was maintained by nonfamily companies. Thus, in a crisis scenario the economic performance of family businesses is superior to non-family businesses. As a contribution, the study presents the economic behavior of family and non-family businesses, indicating how the economic performance of family and non-family businesses behave in a crisis scenario, demonstrating that family businesses tend to maintain higher economic performance.

Keywords: Economic performance. Family businesses. Non-family companies. Crisis 2012.

\section{INTRODUÇÃO}

As corporações estão expostas a inúmeros elementos, como mudanças políticas, econômicas, sociais e de nível de consumo e crises econômicas (Goes, Martins, \& Machado, 2017). Os efeitos das crises econômicas são quase que imediatamente refletidos pelos mercados de capitais, quando ocorrem as oscilações nas bolsas de valores, influenciando o desempenho das organizações. 
Em um cenário de crise, o menor retorno esperado nos investimentos pode agravar o incentivo, reduzindo o investimento de uma empresa no futuro; e diminuir a probabilidade de que a empresa pague sua dívida (D'Aurizio, Oliviero, \& Romano, 2015). Para os autores, as empresas familiares podem ser percebidas como mais solventes porque têm menos incentivos para a inadimplência no futuro, mantendo-se atuantes em um cenário de crise. Meier, Bozec, e Laurin (2013) defendem que a flexibilidade financeira das empresas é um diferencial no cenário de crise, empresas que não dependem exclusivamente de capital de terceiros absorvem mais rapidamente os impactos das crises econômicas mundiais (Lopes, Costa, Carvalho, \& Castro, 2016).

A literatura identificou os atributos únicos das empresas familiares (Lee, 2006). Para Denison, Lief, e Ward (2004), Gentry, Dibrell, e Kim (2016) e Hall, Melin e Nordqvist (2001), a cultura nas empresas familiares pode ser mais forte, já que os membros da família muitas vezes promulgam valores, assumindo papéis ativos e de longo prazo na gestão. A literatura sobre negócios familiares afirma que as empresas familiares possuem vantagens e desvantagens (Lansberg, 1983; Hiebl, Feldbauer-Durstmüller, \& Duller, 2013; Tagiuri \& Davis, 1992). Entre as vantagens, identifica-se um monitoramento mais próximo, uma perspectiva de longo prazo, maior objetividade entre os acionistas, tomada de decisão mais rápida e cultura mais forte vinda dos valores familiares. Já as fraquezas estão relacionadas a problemas familiares e comerciais, falta de planejamento de sucessão, nepotismo, resistência à mudança e profissionalização (Martínez, Stöhr, \& Quiroga, 2007).

Ainda, as propriedades familiares, em vez de procurarem maximizar os lucros e aumentar o valor dos acionistas, podem seguir estratégias que privilegiem o crescimento, a inovação tecnológica ou a sobrevivência da empresa (Martínez et al., 2007). Ainda, algumas empresas familiares possuem gerentes altamente educados que tomam decisão analítica e algumas empresas não familiarizadas treinaram casualmente seus gestores usando a tomada de decisão intuitiva (Stewart, \& Hitt, 2012).

Além disso, os membros da família com concentração de propriedade têm mais incentivos para maximizar o desempenho de uma empresa e também têm o poder de fazêlo, ao contrário de diversos investidores em uma empresa não familiar (Lee, 2006). Dessa maneira, elaborou-se a seguinte questão-problema: Qual o comportamento do desempenho econômico das empresas familiares e não familiares na Crise de 2012? O objetivo do estudo consiste em analisar o comportamento do desempenho econômico das empresas familiares e não familiares na Crise de 2012.

Como ocorrido nos países europeus, o Governo brasileiro também adotou políticas de enfrentamento a crises mundiais. Nesse sentido, Lopes et al. (2016) destacam que cabe analisar como as empresas determinam as estratégia no enfrentamento das crises econômicas. Para os autores, o Brasil ainda sofre as consequências de crises. Portanto, sabese que as empresas brasileiras sofreram com crises econômicas mundiais e que, desse modo, 
ainda existe uma carência de estudo sobre o efeito das crises nessas empresas (Lopes et al., 2016). Segundo os autores, tal evidência faz com que seja latente a necessidade de pesquisas nessa área.

É largamente conhecido que as empresas familiares influenciam as atividades e o crescimento econômico em todo o mundo (Hiebl et al., 2013). Especialmente no Brasil, muitas empresas influentes são controladas por famílias (Nelson \& Pimentel, 2015). No entanto, precisa-se de mais pesquisas sobre empresas familiares (Bertrand \& Schoar, 2006; Bocatto, Gispert e Rialp, 2010; Khanna \& Yafeh, 2007). Além disso, a pesquisa sobre empresas familiares tem vivenciado um importante momento em termos de produção científica (Borges, Brito, Lima, \& Castro, 2016).

Embora a pesquisa sobre questões de negócios familiares tenha aumentado nos últimos anos, muitas áreas ainda precisam ser examinadas para obterem uma compreensão mais completa do negócio familiar (Goes et al., 2017; Wortman, 1994). Para Gudmundson, Hartman, e Tower (1999) ainda há muito a aprender sobre como as empresas familiares e não familiares e seus comportamentos gerenciais entre empresas familiares e não familiares podem variar em diferentes situações (Gudmundson et al., 1999; Hiebl et al., 2013).

Os resultados do estudo demonstraram que nos anos próximos à Crise de 2012 as empresas familiares obtinham valores de desempenho econômico superiores aos das empresas não familiares, o que as levaram a alcançar melhor posicionamento na distância $\mathrm{DP}_{2}$. Desse modo, em um cenário de crise as empresas familiares tentem a apresentar maior desempenho econômico, mantendo maiores rendimentos a seus proprietários.

Assim, este estudo contribui analisando o comportamento do desempenho econômico das empresas familiares e não familiares brasileiras de capital aberto em um cenário de crise. A pesquisa foi realizada por meio de análise quantitativa, e utilizou-se o modelo de ranking, distância $\mathrm{DP}_{2^{\prime}}$ buscando evidenciar as empresas melhores ranqueadas no período de crise, nesse caso empresas familiares e não familiares. A relevância do estudo consiste na importância de se avaliar o impacto das crises financeiras nessas empresas e verificar como a composição proprietária das empresas influencia na sua continuação, mesmo em um cenário econômico negativo.

\section{REVISÃO DA LITERATURA}

\subsection{A CRISE DE 2012 E OS EFEITOS NO BRASIL}

O atentado de 11 de setembro de 2001, ocorrido nos Estados Unidos, provocou espanto e receio no mundo todo, iniciando a recessão no mercado financeiro. $O$ Banco Central passou 
a reajustar a taxa de juros da economia no intuito de estimular o consumo e promover o crescimento do País (Lopes et al., 2016; Azevedo e Souza, 2011). Os cortes sucessivos na taxa de juros que ocasionaram uma taxa baixa e crédito farto e fácil levaram a um grande aumento no número de empréstimos (Paula, 2009).

Com a perda causada pela baixa taxa de juros e o fato de que os mutuários se encontravam endividados e não contraíam mais empréstimos, os bancos aumentaram o volume de concessões de crédito, resultando na expansão da carteira de crédito (Paula, 2009). Desse modo, as instituições financeiras passaram a conceder crédito a mutuários com histórico e dificuldades financeiras, que dispunham de remuneração abaixo do esperado e alguns com ocorrência passada de inadimplência (Lopes et al., 2016).

Dessa maneira, inicia-se a crise financeira, denominada crise subprime (Lane, 2012; Lopes et al., 2016). Segundo Borça e Torres (2008), a crise subprime provocou uma queda na projeção de crescimento no ano de 2008 , causada pela desaceleração da economia mundial.

Os efeitos da crise afetaram os países do mundo todo. Os países mais afetados se encontram na Zona do Euro, onde o endividamento pós-crise atingiu níveis elevados, percebido mais fortemente entre os anos 2011 e 2012. A crise da Zona do Euro iniciou após o crescimento da dívida pública dos países europeus (Lane, 2012), afetando diferentes economias mundiais.

Segundo Lane (2012) alguns fatores estimularam a crise da Zona do Euro nos anos de 2011 a 2012. Para o autor, as falhas das políticas fiscais, a desvalorização do euro, a dificuldade em analisar e implantar políticas orçamentárias, o crescimento do endividamento após a crise subprime e a falta de investidores de países estrangeiros aceleraram a crise instaurada em 2011 e 2012.

Segundo Matias-Pereira (2009), a economia brasileira entrou em um período de recessão, iniciado no último trimestre de 2008. Para Marouelli (2009), o primeiro semestre de 2008 foi marcado por um grande aumento no preço das commodities, influenciado pela expansão do consumo, gerando uma situação favorável às empresas brasileiras.

O Governo brasileiro, no intuito de amenizar os efeitos da crise subprime, implementou políticas anticíclicas, tanto monetárias quanto fiscais. As políticas fiscais incluíram desonerações fiscais, a fim de impulsionar a produção e a geração de empregos; e incentivo ao crédito pessoal e empresarial por meio dos bancos públicos (Lopes et al., 2016).

Para Prates, Cunha, e Lélis (2011), o contexto de forte redução das margens de capacidade ociosa e demanda aquecida, somado à alta dos preços das commodities resultaram na aceleração da inflação em várias economias emergentes. Assim, a resposta convencional deveria ter sido a adoção de uma política monetária restritiva para desacelerar o crescimento e conter as pressões inflacionárias. Dessa forma, a partir da Crise de 2012, 
entendeu-se que medidas anticíclicas não eram as mais adequadas ao momento, mas medidas restritivas, que levassem ao maior equilíbrio financeiro (Lopes et al., 2016).

\section{FUNDAMENTAÇÃO DAS HIPÓTESES}

Assim como em outros países, o Brasil também sofreu com os impactos causados pela crise subprime e consequentemente a crise da Zona do Euro (Lopes et al., 2016). Lopes et al. (2016) analisaram o comportamento do valor de mercado das empresas brasileiras de capital aberto em relação à sua situação econômico-financeira nos anos de 2008 e 2012. Para os autores, é necessário que se conheça o efeito das crises financeiras nas empresas e se verifique se o mercado avalia as estratégias econômicas mantidas pelas empresas para o enfrentamento das crises econômicas.

Estudos analisaram características distintas entre empresas familiares e não familiares (Anderson \& Reeb, 2003; Coleman \& Carsky, 1999; Gudmundson et al., 1999; Hiebl et al., 2013; Lee \& Rogoff, 1996; Westhead, Cowling, \& Howorth, 2001). Esses estudos demostraram resultados mistos, sendo que as empresas familiares e não familiares são diferentes em algumas dimensões, como atividades empresariais realizadas, desempenho, percepção de oportunidades e ameaças ambientais, mas não em outros estudos, como orientação estratégica e fontes de financiamento da dívida.

Dados sobre o ciclo econômico sugerem que durante as recessões temporárias do mercado as empresas familiares podem sofrer tanto quanto as empresas não familiares (Lee, 2006). No entanto, a empresa familiar inculca mais continuidade das suas atividades e estabilidade econômica ao longo do tempo, bem como na estabilidade do emprego de seus subordinados (Lee, 2006).

Pesquisas demonstraram que as empresas familiares são significativamente melhores do que as empresas não familiares (Martínez et al., 2007; Hiebl et al., 2013). Anderson e Reeb (2003) examinaram se há um efeito da propriedade familiar sobre o desempenho da empresa. Os resultados demonstram que as empresas familiares superaram significativamente as empresas não familiares. Já, Gallo e Estapé (1992) descobriram que as empresas familiares possuem ROE mais elevado do que as não familiares. Martínez (1994) evidenciou uma diferença, mas não significativa, em favor das empresas familiares.

No entanto, pesquisas evidenciaram que as empresas familiares tendem a favorecer os membros da família no preenchimento de posições de gestão, o que leva a desvantagens competitivas com relação às empresas não familiares (Gómez-Mejía, Nunez-Nickel, \& Gutiérrez, 2001). Além disso, Villalonga e Amit (2006) evidenciaram que a empresa familiar cria valor somente quando o fundador atua como CEO ou presidente dela. Morck e Yeung (2003) evidenciaram que a propriedade e o controle da família tendem a resultar em 
desempenho deficiente da empresa. Para Gallo, Tàpies, e Cappuyns (2004) as não familiares possuem um desempenho mais elevado do que as empresas familiares.

Nas empresas não familiares o administrador precisa equilibrar os interesses dos gestores no crescimento da empresa versus os interesses dos demais proprietários e possuidores de diferentes quantidades de ações (Nelson \& Pimentel, 2015). Já nas empresas familiares os gestores enfrentam diversos objetivos conflitantes, como crescimento versus retorno, interesses de emprego dos membros da família, pressões para usar os ativos de forma a favorecer pessoalmente os membros da família, imagem da família, identidade e legado dos fundadores (Nelson \& Pimentel, 2015).

Thomsen e Pedersen (2000) pesquisaram as relações entre os tipos de propriedade e o desempenho organizacional. Os resultados do estudo demonstraram que as famílias que são acionistas majoritárias maximizam as vendas; além disso, evidenciaram que a identidade do proprietário é uma importante variável para entender às relações entre a estrutura da propriedade e o desempenho organizacional. Segundo Campos (2006) as empresas familiares fazem grande investimento em capital humano, adquirindo vantagens e capacitando seus subordinados para a atividade administrativa. Ainda, são mais avessas ao risco, reduzindo as possibilidades de acesso a recursos e projetos de investimento. Além disso, as empresas familiares tendem a investir de forma mais eficiente porque entendem que suas empresas são como um ativo para transmitir para as gerações futuras (Lee, 2006).

D'Aurizio et al. (2015) analisaram os efeitos econômicos da crise financeira para detectar possíveis diferenças entre empresas familiares e não familiares nos anos de 2007 a 2009. Os resultados do estudo demonstraram que não há diferença significativa entre empresas familiares e não familiares em termos de investimento (tangível ou intangível), mas há uma diferença significativa na mudança no número de funcionários.

Para Martínez et al. (2007) o envolvimento familiar não tem um efeito significativo no desempenho quando comparado com empresas similares não familiares. No entanto, teóricos destacam que os processos de planejamento estratégico e as estratégias das empresas familiares diferem significativamente dos processos e estratégias das empresas não familiares (Harris, Martinez, \& Ward, 1994; Ward, 1988), podendo interferir significativamente no seu desempenho econômico nos cenários de crises econômicas enfrentados pelas empresas. Assim, elaborou-se a hipótese $H_{1}$ de pesquisa:

$H_{1}$ : Existe diferença no comportamento do desempenho econômico das empresas familiares e não familiares na Crise de 2012. 


\section{MÉTODO E PROCEDIMENTOS DA PESQUISA}

Para analisar o comportamento do desempenho econômico das empresas familiares e não familiares na Crise de 2012 de empresas brasileiras listadas na B3 (Brasil, Bolsa, Balcão), esta pesquisa é definida quanto aos objetivos como descritiva. A abordagem do problema é caracterizada como uma pesquisa quantitativa. Além disso, a pesquisa configura-se também como de análise documental.

Para a caracterização das empresas em empresas familiares, utilizou-se a proposta de Donnelley (1964). Para o autor, é possível adotar um ou mais critérios, como: sucessão administrativa, parentes do atual ou antigos diretores têm assento no Conselho de Administração, os valores das empresas se alinham aos valores da família e membros da família sentem-se na obrigação de adquirir ações da empresa, No entanto, para identificar neste estudo se a empresa se caracterizava como familiar ou não, verificou-se a presença de membros da família no Conselho de Administração.

A população do estudo compreende as empresas familiares e não familiares listadas na B3, consistindo em 480 empresas. A amostra da pesquisa engloba as empresas brasileiras que demostraram todas as informações para os cálculos dos indicadores econômicos. Selecionaram-se as empresas que continham informações no período de 2008 a 2016, das quais resultou em uma amostra de 261 empresas, apresentando 2.349 observações. Na Tabela 1 são apresentadas as variáveis de forma mais detalhada e os indicadores de desempenho econômico analisados no estudo:

Tabela 1

Variáveis utilizadas na pesquisa

\begin{tabular}{llll}
\hline \multicolumn{1}{c}{ VARIÁVEL } & \multicolumn{1}{c}{ DEFINIÇÃO } & \multicolumn{1}{c}{ COLETA } & \multicolumn{1}{c}{ AUTORES } \\
\hline $\begin{array}{l}\text { Empresas familiares } \\
\text { Período de crise }\end{array}$ & $\begin{array}{l}\text { Presença de membros } \\
\text { da família no Conselho } \\
\text { de Administração } \\
\text { PIB negativo }\end{array}$ & $\begin{array}{l}\text { B3 } \\
\text { Formulário de } \\
\text { Referência } \\
\text { Banco Central }\end{array}$ & $\begin{array}{l}\text { Donnelley (1964) } \\
\text { Lopes et al. (2016) }\end{array}$ \\
\hline $\begin{array}{l}\text { Retorno sobre o Ativo } \\
\text { (ROA) }\end{array}$ & INDICADORES DE DESEMPENHO ECONÔMICO \\
$\begin{array}{l}\text { Retorno sobre o Patri- } \\
\text { mônio Líquido (ROE) }\end{array}$ & & $\begin{array}{l}\text { Caylor e Lopez (2013), Shaw e Zhang } \\
\text { (2010), Via e Perego (2013) }\end{array}$ \\
$\begin{array}{l}\text { Lucro Operacional } \\
\text { sobre o Ativo (LOP) }\end{array}$ & Economatica & $\begin{array}{l}\text { Bomfim, Teixeira, e Monte (2015) } \\
\text { Chiarello, Silva, e Nakamura (2014) e }\end{array}$ \\
$\begin{array}{l}\text { Margem Líquida } \\
\text { (MGL) }\end{array}$ & & $\begin{array}{l}\text { Oro, Beuren, e Hein (2009) } \\
\text { Beuren, Hein, e Cavassola (2007) e } \\
\text { Dal Magro, Di Domenico, Klann, e }\end{array}$ \\
\hline
\end{tabular}


Os dados coletados foram tabulados em planilhas eletrônicas para a realização dos cálculos. Para a análise dos dados, inicialmente foi realizada a Estatística de análise descritiva, com o auxílio dos programas Microsoft Excel ${ }^{\circ}$, em seguida o Teste de normalidade dos dados. Após a apresentação dessas análises, apresentam-se os resultados para que a hipótese de pesquisa seja aceita ou rejeitada, pelo método estatístico distância $\mathrm{DP}_{2}$.

A distância $\mathrm{DP}_{2}$ é um indicador sintético elaborado por Trapero (1977) que tem por finalidade a comparação interespacial e/ou intertemporal de variáveis. Há duas vantagens inerentes ao método: a primeira é a atribuição de pontuação a cada elemento envolvido na análise, formando um ranking dos elementos envolvidos frente ao que a realidade permite, ou seja, o método trabalha com pontos de referência hierarquicamente construídos. A segunda vantagem é a possibilidade da mensuração de disparidades entre os envolvidos.

O método necessita de uma matriz, cujos elementos em linha são, no caso deste estudo, as empresas em análise, e as colunas as variáveis a serem sintetizadas. Cada elemento $x_{i j}$ da matriz representa o valor associado da empresa i na variável j.

O indicador sintético é construído segundo a completitude e a linearidade. Especificamente, completitude: o número das componentes é tal que todas as propriedades relacionadas com o objeto buscado pelo indicador global são representadas por meio de suas componentes (variáveis); linearidade: a relação existente entre os distintos componentes é linear, ou seja, $x_{j}=\alpha_{0}+\alpha_{1} x_{1}+\cdots+\alpha_{j-1} x_{j-1}+\varepsilon_{j-1}$; para $\mathrm{j}=1, \ldots, \mathrm{n}$. Com essa suposição, define-se a distância $\mathrm{DP}_{2}$ na Fórmula 1:

$$
x_{j}=\alpha_{0}+\alpha_{1} x_{1}+\cdots+\alpha_{j-1} x_{j-1}+\varepsilon_{j-1}
$$

Sendo:

$$
\begin{aligned}
& d_{j}=d_{j}(r, k)=\left|x_{r j}^{*}-x_{i j}\right| \text {, em que r é base de referência; } \\
& \frac{d_{j}}{\sigma_{j}} \text { é o indicador parcial da componente j (variável). }
\end{aligned}
$$

Ao dividir a distância $d_{j}$ pelo desvio padrão da componente, o indicador perde as unidades nas quais foi mensurado. Esse procedimento soluciona o problema de heterogeneidade das unidades de medida dos indicadores parciais e, por outro lado, serve como sistema de ponderação mediante o qual se consegue dar menor importância às distâncias correspondentes às componentes cujos valores apresentem maior dispersão em relação à média. O fator $\left(1-R_{j, j-1, j-2, \ldots, 1}^{2}\right)$ evita a duplicidade de informação, ou seja, 
elimina indicadores parciais da informação já contida em outros indicadores precedentes (Zarzosa, 1996).

Contudo, há uma discussão anterior à aplicação do método $\mathrm{DP}_{2^{\prime}}$ pois seus resultados variam dependendo da ordem de entrada das componentes (variáveis). Nesse sentido, é imperativo fixar uma hierarquia de entrada de variáveis. $O$ critério lógico de ordenação é o de atender à quantidade de informação sobre o objeto a mensurar e ao que cada indicador aporta ao indicador sintético.

A hierarquia assumida neste estudo foi de verificar a distância de Frechet, que é o máximo valor que a distância $\mathrm{DP}_{2}$ pode assumir e a qual é definida como a soma dos indicadores parciais, como segue:

$$
F_{j}=\sum_{j=1}^{n} \frac{d_{j}}{\sigma_{j}}
$$

Em linhas gerais, pode-se formular o algoritmo para o cálculo do $\mathrm{DP}_{2}$ dos indicadores econômicos das empresas familiares e não familiares:

a) Estabelecimento da matriz de valores das componentes das m empresas envolvidas;

b) Verificação dos critérios das n variáveis envolvidas quanto a sua conduta, ou seja, classificar as variáveis quanto ao seu objetivo: "quanto maior, melhor" ou "quanto menor, melhor";

c) Eleição da base de referência em cada variável, determinando seu ideal teórico;

d) Cálculo das distâncias de Frechet;

e) Ordenação das componentes de maior para menor à hierarquização do modelo;

f) Obtenção do $\mathrm{DP}_{2}$ de cada empresa fazendo entrar as componentes segundo a hierarquia definida em ( $v$ );

g) Iterações consecutivas até que todas as variáveis tenham sido incorporadas ao modelo.

Destaca-se que é necessário verificar que quanto maior a distância $D_{2}$ de um elemento, mais longe ele estará do valor teórico de referência. Assim, quanto maior o valor do $\mathrm{DP}_{2}$ (empresa), mais bem posicionada ela estará em caso da formação de um ranking. 


\section{APRESENTAÇÃO E ANÁLISE DOS RESULTADOS}

Esta seção apresenta a descrição e a análise dos resultados encontrados na presente pesquisa. Inicialmente, apresenta-se a estatística descritiva das variáveis. A estatística descritiva das variáveis utilizada no presente estudo foi calculada, realizando-se o teste de diferença de médias, mediana, desvio padrão, máximos e mínimos, conforme a Tabela 2:

Tabela 2

Estatística descritiva das variáveis

\begin{tabular}{llllll}
\hline \multicolumn{1}{c}{ Variável } & Média & $\begin{array}{c}\text { Desvio } \\
\text { padrão }\end{array}$ & Mediana & Máximo & Mínimo \\
\hline $\begin{array}{l}\text { Retorno sobre o Ativo (ROA) } \\
\begin{array}{l}\text { Retorno sobre o Patrimônio Líquido } \\
\text { (ROE) }\end{array}\end{array}$ & 0,0436 & 0,1056 & 0,0411 & 0,8975 & $-1,7977$ \\
$\begin{array}{l}\text { Lucro Operacional sobre o Ativo (LOP) } \\
\text { Margem Líquida (MGL) }\end{array}$ & 0,0820 & 0,1113 & 0,0722 & 1,0602 & $-1,6432$ \\
\hline
\end{tabular}

Na Tabela 2 observa-se a média e o desvio padrão nos anos 2008 a 2016 das medidas de desempenho econômico ROA, ROE, LOP e MGL das empresas analisadas no estudo. Percebe-se que a média do Retorno sobre o Patrimônio Líquido (ROE) se apresentou em $\mathrm{R} \$$ 0,134, a Margem Líquida (MGL) em 0,0866. Esse resultado sugere uma tendência de as empresas possuírem maiores ROA e MGL.

Para o cálculo do $\mathrm{DP}_{2^{\prime}}$ é necessário que exista uma hierarquia da ordem das variáveis analisadas no estudo, as quais são classificadas como de entrada e os cálculos interativos até haver uma convergência entre os resultados sucessivos (Somarriba \& Pena, 2008). A Tabela 3 demonstra os resultados obtidos mediante a aplicação da distância $\mathrm{DP}_{2}$ para uma amostra de 15 empresas separadas em empresas familiares e não familiares anteriormente à Crise de 2012 (2008, 2009, 2010 e 2011) e posteriormente (2013, 2014, 2015 e 2016). Essas empresas que evidenciaram maior valor de indicador de conformidade (desempenho econômico) estão mais perto dos objetivos do que aquelas com menor valor. 


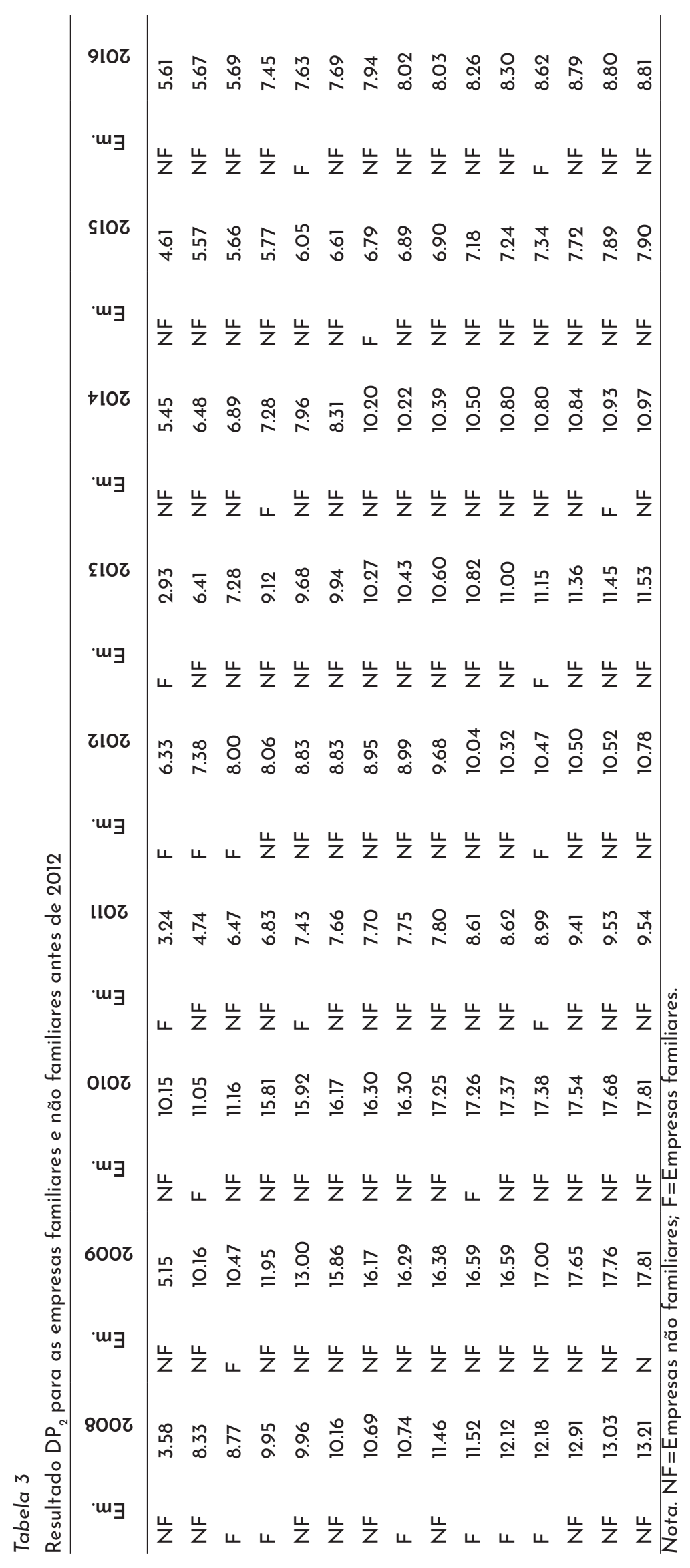


$\mathrm{Na}$ Tabela 3 verifica-se a amostra selecionada das 15 melhores empresas ranqueadas pela distância $\mathrm{DP}_{2}$. Demonstra-se o arranjo das empresas familiares e não familiares, de acordo com o seu desempenho econômico anterior e posteriormente à crise econômica de 2012. Destaca-se que no ano de 2008 seis empresas se apresentaram no ranking das 15 melhores empresas, no entanto, no ano de 2009 verificaram-se somente duas empresas familiares, no ano de 2010 duas empresas foram consideradas como empresas familiares e em 2011 três empresas familiares. No entanto, o melhor posicionamento no ranking para as empresas familiares foi no ano de 2011.

No que se refere às posições no ranking da distância $D_{2}$ para o ano de 2008 a empresa não familiar se demostrou em primeiro lugar com 3,58 de $\mathrm{DP}_{2^{\prime}}$ no ano de $2009 \mathrm{a}$ empresa não familiar se apresentou também em primeiro lugar no ranking com 5,15 de $\mathrm{DP}_{2^{i}}$ em 2010 a empresa que ocupou a primeira colocação foi classificada como não familiar com um $\mathrm{DP}_{2}$ de 10,15; e, por fim, em 2011, diferente dos demais anos, a empresa familiar ocupou a primeira colocação com um $\mathrm{DP}_{2}$ de 3,24 . Assim, percebe-se que nos quatro anos analisados anteriormente à Crise de 2012, as empresa que apresentaram melhor posicionamento no ranking de desempenho econômico foram as não familiares, no entanto, tal comportamento não foi identificado no ano de 2011, ano próximo à Crise de 2012.

Tal evidência pode ocorrer pelo fato de nas empresas não familiares o administrador precisar equilibrar os interesses dos gestores no crescimento da empresa versus os interesses dos demais proprietários e possuidores de diferentes quantidades de ações (Nelson \& Pimentel, 2015), impulsionando o desempenho econômico da empresa. Já nas empresas familiares os gestores enfrentam objetivos que incluem o crescimento versus o retorno, os interesses de emprego dos membros da família, pressões para usar os ativos de forma a favorecer os membros da família, a imagem da família, bem como os diversos interesses dos empregados (Nelson \& Pimentel, 2015).

Percebe-se que no ano de 2012 quatro empresas são empresas familiares, no ano de 2013 três empresas são categorizadas como empresas familiares, no ano de 2014 duas empresas são classificadas como empresas familiares, no ano de 2015 uma empresa é empresa familiar, e, por fim, no ano de 2016, duas empresas são familiares. Dessa maneira, percebese que a quantidade de empresas familiares no ranking diminuiu, quando comparado com o ranqueamento das empresas familiares e não familiares anteriores ao período da Crise de 2012. Isso indica que após a Crise de 2012 as empresas não familiares se recuperaram, atingindo melhores índices de desempenho econômico.

Além disso, verifica-se que no ano de 2012 a empresa que apresentou maior distância $D_{2}$ (3.24) é classificada como empresa familiar. No ano de 2013 a empresa familiar apresentou maior distância $\mathrm{DP}_{2}$ (2.93). Contudo, no ano de 2014, em primeiro lugar no ranking $\mathrm{DP}_{2}$ (5.45), ficou a empresa considerada como empresa não familiar. No seguinte ano, 2015, a empresa classificada em primeiro lugar no ranking $\operatorname{DP}_{2}(4.61)$ é qualificada como 
não familiar. Por fim, no ano de 2016, a empresa classificada em primeiro lugar DP2 (5.61) é uma empresa não familiar.

Assim, percebe-se uma mudança no comportamento econômico das empresas, principalmente nos anos de 2011, 2012 e 2013; as empresas familiares passaram a ocupar o primeiro lugar no ranking de desempenho econômico, o que demonstra que no cenário da Crise de 2012 o desempenho econômico das empresas familiares é superior ao das empresas não familiares. No entanto, nota-se que a partir de 2015 as empresas não familiares se apresentam com maiores índices de $\mathrm{DP}_{2}$. Isso indica que com o passar dos anos as empresas não familiares começaram a recuperar seu desempenho econômico.

Conforme os achados evidenciados na Tabela 3, verifica-se que existe um comportamento diferenciado das empresas familiares e não familiares no cenário de Crise de 2012, dessa forma, confirma-se a hipótese de pesquisa $H_{r}$ : Existe diferença no comportamento do desempenho econômico das empresas familiares e não familiares na Crise de 2012. Os achados deste estudo divergem dos de D'Aurizio et al. (2015), que demonstraram que não há diferença significativa entre empresas familiares e não familiares em termos econômicos em um cenário de crise.

No entanto, este achado corrobora os estudos de Anderson e Reeb (2003), Coleman e Carsky (1999), Gudmundson et al. (1999), Lee e Rogoff (1996) e Westhead et al. (2001), que demonstraram que as empresas familiares e não familiares se comportam de maneiras diferentes quando se refere a um ambiente econômico.

Anderson e Reeb (2003) evidenciaram que as empresas familiares superam significativamente as empresas não familiares. Gallo e Estapé (1992) descobriram que as empresas familiares possuem ROE mais elevado do que as não familiares. Conforme demonstrado neste estudo, as empresas familiares possuem maior desempenho econômico quando as empresas enfrentam um cenário de crise mundial, sendo menos sensíveis a tais eventos.

Segundo Campos (2006), as empresas familiares realizam investimentos em capital humano, adquirindo vantagens por meio da capacitação dos seus subordinados para as atividades administrativas. Ainda, as empresas familiares são mais avessas ao risco, reduzindo as possibilidades de acesso a recursos e projetos de investimento. Tais fatores podem contribuir para que as empresas familiares sejam mais resistentes em seu desempenho econômico quando enfrentam um cenário de crise. 


\section{CONSIDERAÇÕES FINAIS}

O objetivo da pesquisa consistiu em analisar o comportamento do desempenho econômico das empresas familiares e não familiares na Crise de 2012. Para tanto, realizouse uma pesquisa descritiva, documental e quantitativa. A amostra compreendeu 2.349 observações de 261 empresas, das quais foram classificadas em empresas familiares e não familiares nos nove anos analisados, de 2008 a 2016.

Para a análise dos resultados foram utilizados diferentes testes estatísticos, como estatística descritiva e distância $\mathrm{DP}_{2} \mathrm{~A}$ distância $\mathrm{DP}_{2}$ é um indicador sintético que tem por finalidade a comparação interespacial e/ou intertemporal de variáveis. $O$ método $D_{2}$ atribui uma pontuação a cada elemento envolvido na análise, formando um ranking dos elementos analisados na pesquisa.

De maneira geral, os resultados demonstraram nos anos anteriormente à Crise de 2012 , os anos que apresentaram melhor indicador $D_{2}$ para as empresas familiares foram 2011, 2012 e 2013. Dessa maneira, nota-se que nos anos próximos à Crise de 2012 as empresas familiares obtinham valores de desempenho econômico superiores às empresas não familiares, o que as levaram a alcançar melhor posicionamento no ranking. Além disso, percebe-se que nos quatro anos avaliados anteriormente à Crise de 2012, as empresa que apresentaram melhor desempenho econômico foram as empresas não familiares, assim, verificou-se um comportamento diferenciado nos anos anteriores e posteriores à crise entre as empresas familiares e não familiares, o que possibilitou confirmar a Hipótese $H_{1}$.

Conclui-se uma mudança no comportamento econômico das empresas familiares e não familiares principalmente nos anos de 2011, 2012 e 2013; as empresas familiares passaram a ocupar o primeiro lugar no ranking de desempenho econômico, o qual anteriormente era mantido pelas empresas não familiares. Além disso, em um cenário de crise, o desempenho econômico das empresas familiares é superior ao das empresas não familiares.

Como contribuição, o estudo demostra o comportamento econômico das empresas familiares e não familiares, indicando como as empresas familiares e não familiares se comportam em um cenário de crise. Além disso, analisou-se um cenário de crise, e sobre este, sabe-se que as empresas brasileiras sofreram com crises econômicas (Lopes et al., 2016), sendo de suma importância a sua investigação.

As limitações deste estudo consistem na impossibilidade da generalização dos resultados em razão do número limitado de empresas e do horizonte temporal de análise, além dos modelos adotados para o desempenho econômico. Dessa forma, sugere-se, para estudos futuros, a inclusão de novos períodos de análise, empresas de outros países e outros indicadores de desempenho que podem sofrer influência indireta e impactar o comportamento das empresas em um cenário de crise. 


\section{REFERÊNCIAS}

Anderson, R. C., \& Reeb, D. M. (2003). Founding family ownership and firm performance: Evidence from the S\&P 500. The journal of finance, 58(3), 1301-1328.

Azevedo, L. A., \& Souza, D. A. (2011). Do Crash ao Subprime: Uma análise da concessão de crédito no Brasil. Anais do Encontro de Economia Catarinense-Finanças e Economia do Setor Público, Florianópolis, 5.

Beuren, I. M., Hein, N., \& Cavassola, J. A. (2007). Participação de Mercado e Criação de Valor: Um Estudo de Empresas do Varejo Automobilístico em Santa Catarina. RACEletrônica, 1(3).

Bomfim, E. T. D., Teixeira, W. D. S., \& Monte, P. A. D. (2015). Relação entre o disclosure da sustentabilidade com a governança corporativa: Um estudo nas empresas listadas no Ibrx-100. Sociedade, Contabilidade e Gestão, 10(1).

Borça, G. R., Jr., \& Torres, E. T., Filho. (2008). Analisando a crise do subprime. Revista do BNDES, 15(30), 129-159.

Campos, T. L. C. (2006). Estrutura da propriedade e desempenho econômico: Uma avaliação empírica para as empresas de capital aberto no Brasil. Revista de AdministraçãoRAUSP, 41(4).

Chiarello, T. C., Silva, T. P. da, \& Nakamura, W. T. (2014). Efeito das Estratégias Financeiras Alinhado à Política de Dividendos das Empresas de Propriedade Familiar e Não Familiar Brasileiras. Advances in Scientific \& Applied Accounting, 7(3).

Coleman, S., \& Carsky, M. (1999). Sources of capital for small family-owned businesses: Evidence from the national survey of small business finances. Family Business Review, 12(1), 73-84.

Bertrand, M., \& Schoar, A. (2006). The role of family in family firms. Journal of economic perspectives, 20(2), 73-96.

Bocatto, E., Gispert, C., \& Rialp, J. (2010). Family owned business succession: the influence of pre performance in the nomination of family and nonfamily members: Evidence from Spanish firms. Journal of Small Business Management, 48(4), 497-523.

Borges, A. F., Brito, M. J. D., Lima, J. B. D., \& Castro, C. L. D. C. (2016). 
Empreendedorismo em empresas familiares: A pesquisa atual e os desafios futuros. RAM. Revista de Administração Mackenzie, 17(2), 93-121.

Caylor, M. L., \& Lopez, T. J. (2013). Cost behavior and executive bonus compensation. Advances in Accounting, 29(2), 232-242.

Dal Magro, C. B., Di Domenico, D., Klann, R. C., \& Zanin, A. (2013). Contabilidade rural: Comparativo na rentabilidade das atividades leiteira e avícola. Custos e@ gronegócio on-line, 9.

D'Aurizio, L., Oliviero, T., \& Romano, L. (2015). Family firms, soft information and bank lending in a financial crisis. Journal of Corporate Finance, 33, 279-292.

Denison, D., Lief, C., \& Ward, J. L. (2004). Culture in family owned enterprises: Recognizing and leveraging unique strengths. Family Business Review, 17(1), 61-70.

Donnelley, R. G. (1964). The family business. Harvard Business Review, 42(4), 93-105.

Gallo, M. A., \& Estapé, M. J. (1992). Family business among the top 1000 Spanish companies. IESE research paper, 231.

Gallo, M. Á., Tàpies, J., \& Cappuyns, K. (2004). Comparison of family and nonfamily business: Financial logic and personal preferences. Family Business Review, 17(4), 303-318.

Gentry, R., Dibrell, C., \& Kim, J. (2016). Long-Term Orientation in Publicly Traded Family Businesses: Evidence of a Dominant Logic. Entrepreneurship Theory and Practice, 40(4), 733-757.

Goes, T. H. M., Martins, H. H., \& Machado, C. A. P., Filho. (2017). Desempenho financeiro de empresas com características familiares: Análise de empresas brasileiras listadas na BM\&F. REGE-Revista de Gestão, 24(3), 197-209.

Gómez-Mejía, L. R., Nunez-Nickel, M., \& Gutiérrez, I. (2001). The role of family ties in agency contracts. Academy of management Journal, 44(1), 81-95.

Gudmundson, D., Hartman, E. A., \& Tower, C. B. (1999). Strategic orientation: Differences between family and nonfamily firms. Family Business Review, 12(1), 27-39.

Hall, A., Melin, L., \& Nordqvist, M. (2001). Entrepreneurship as radical change in the family business: Exploring the role of cultural patterns. Family Business Review, 14(3), 193-208. 
Harris, D., Martinez, J. I., \& Ward, J. L. (1994). Is strategy different for the family owned business? Family business review, 7(2), 159-174.

Hiebl, M. R., Feldbauer-Durstmüller, B., \& Duller, C. (2013). The changing role of management accounting in the transition from a family business to a non-family business. Journal of Accounting \& Organizational Change, 9(2), 119-154.

Khanna, T., \& Yafeh, Y. (2007). Business groups in emerging markets: Paragons or parasites? Journal of Economic literature, 45(2), 331-372.

Lane, P. R. (2012). The European sovereign debt crisis. The Journal of Economic Perspectives, 26(3), 49-67.

Lansberg, I. S. (1983). Managing human resources in family firms: The problem of institutional overlap. Organizational dynamics, 12(1), 39-46.

Lee, J. (2006). Family firm performance: Further evidence. Family business review, 19(2), $103-114$.

Lee, M. S., \& Rogoff, E. G. (1996). Research note: Comparison of small businesses with family participation versus small businesses without family participation: An investigation of differences in goals, attitudes, and family/business conflict. Family Business Review, 9(4), 423-437.

Lopes, P. F., Costa, D. F., Carvalho, F. de M., \& de Castro, L. G., Jr. (2016). Desempenho econômico e financeiro das empresas brasileiras de capital aberto: Um estudo das crises de 2008 e 2012. Revista Universo Contábil, 12(1), 105.

Marouelli, R. P. (2009). Crise mundial nos preços dos alimentos: Oportunidades e desafios para a agricultura brasileira (Monografia de especialização). Universidade de Brasília, Brasília, DF.

Martínez, J. I. (1994). Family business in Chile. Health, 1(3), 4.

Martínez, J. I., Stöhr, B. S., \& Quiroga, B. F. (2007). Family ownership and firm performance: Evidence from public companies in Chile. Family Business Review, 20(2), 83-94.

Matias-Pereira, J. (2009). Manual de gestão pública contemporânea. São Paulo: Atlas.

Meier, I., Bozec, Y., \& Laurin, C. (2013). Financial flexibility and the performance during the recent financial crisis. International Journal of Commerce and Management, 23(2), 79-96. 
Morck, R., \& Yeung, B. (2003). Agency problems in large family business groups. Entrepreneurship theory and practice, 27(4), 367-382.

Nelson, R. E., \& Pimentel, T. D. (2015). Uma Perspectiva Weberiana para a Governança de Empresas Familiares: Notas a partir de um estudo com empresas longevas. Organizações \& Sociedade, 22(75), 539-560.

Oro, I. M., Beuren, I. M., \& Hein, N. (2009). Análise da relação entre a estrutura de capital e o lucro operacional nas diversas gerações de empresas familiares brasileiras. Contabilidade Vista \& Revista, 20(1).

Paula, M. R. D. S. M. (2009). Impacto da crise subprime no sector bancário português (Tese de doutorado). Instituto Universitário de Lisboa, Lisboa, Portugal.

Prates, D. M., Cunha, A. M., \& Lélis, M. T. C. (2011). O Brasil e a crise financeira global: Avaliando os canais de transmissão nas contas externas. Revista de Economia Contemporânea, 15(1), 62-91.

Shaw, K. W., \& Zhang, M. H. (2010). Is CEO cash compensation punished for poor firm performance? The Accounting Review, 85(3), 1065-1093.

Somarriba, N., \& Pena, B. (2008). Aproximación a un indicador regional y nacional de los Objetivos de Lisboa a partir de la medida de distancia P2. Estudios Económicos de Desarrollo Internacional, 2, 83-94.

Stewart, A., \& Hitt, M. A. (2012). Why can'ta family business be more like a nonfamily business? Modes of professionalization in family firms. Family Business Review, 25(1), 58-86.

Tagiuri, R., \& Davis, J. A. (1992). On the goals of successful family companies. Family Business Review, 5(1), 43-62.

Thomsen, S., \& Pedersen, T. (2000). Ownership structure and economic performance in the largest European companies. Strategic Management Journal, 689-705.

Trapero, P (1977). Problemas de medición de bienestar y conceptos afines. Madrid: INE.

Via, N. D., \& Perego, P. (2013). Sticky cost behaviour: Evidence from small and medium sized companies. Accounting \& Finance, 54(3), 753-778.

Villalonga, B., \& Amit, R. (2006). How do family ownership, control and management affect firm value? Journal of financial Economics, 80(2), 385-417. 
Ward, J. L. (1988). The special role of strategic planning for family businesses. Family business review, 1(2), 105-117.

Westhead, P., Cowling, M., \& Howorth, C. (2001). The development of family companies: Management and ownership imperatives. Family Business Review, 14(4), 369-385.

Wortman, M. S. (1994). Theoretical foundations for family-owned business: A conceptual and research-based paradigm. Family Business Review, 7(1), 3-27.

Zarzosa, E. (1996). Aproximación a la medición del bienestar social. Valladolid: Universidad de Valladolid-Secretariado Publicaciones.

\section{Como citar este artigo:}

\section{ABNT}

LUNARDI, Micheli Aparecida Lunardi; HEIN, Nelson; KROENKE, Adriana. Desempenho econômico das empresas familiares e não familiares na Crise de 2012. RACE, Revista de Administração, Contabilidade e Economia, Joaçaba: Editora Unoesc, v. 19, n. 1, p. 153-172, jan./abr. 2020. Disponível em: http://editora.unoesc.edu.br/index.php/race. Acesso em: dia/ mês/ano.

\section{APA}

Lunardi, M. A. L., Hein, N., \& Kroenke, A. (2020). Desempenho econômico das empresas familiares e não familiares na Crise de 2012. RACE, Revista de Administração, Contabilidade e Economia, 19(1), 153-172. Recuperado de http://editora.unoesc.edu.br/index.php/ race 